\title{
TRÓPICOS TRISTES Y PARADISÍACOS
}

\author{
Vicente Francisco Torres
}

Resumen: Este artículo continúa las indagatorias del autor sobre la visión de la selva que han dado los hombres de letras en Hispanoamérica. Como un estudio de esta naturaleza no estaría completo sin la presencia de los naturalistas, que coincidieron en equiparar el trópico con el paraíso, el presente trabajo entrega una lectura de ellos y le da cita al antropólogo Claude Lévy-Strauss, quien fue una voz discordante en la visión paradisíaca del trópico.

Palabras clave: naturalistas, viajeros, trópicos, antropólogos, paraíso.

Enviado a dictamen: 25 de abril de 2011 Aprobación: 17 de mayo de 2011 Revisiones: 1

Vicente Francisco Torres, doctor en Antropología por la Universidad Autónoma Metropolitana-Azcapotzalco. Correo electrónico: uftm@correo.azc.uam.mx.
Abstract: This paper continues the author's reserch on how is percived in Latin American Spanish speaking literary circles the tropics as a topic. Given that this study would not be complet without mentioning the writers called naturalists who saw the tropics as paradise itself, this paper also includes a dissentig opinion, that of the anthropologist Claude Lévy-Strauss, who never equated tropics whit paradise.

Keywords: naturalist writers, travelers, tropics, anthropologists, paradise.

\section{1}

$\square$ 1 descubrimiento del Nuevo Mundo produjo un verdadero cisma entre los sabios. Una polémica que tenía lugar en la Academia de Ciencias de París, la cual sesionaba en la bilioteca del Rey Luis XV, habría de tener hondas repercusiones en el estudio y conocimiento del mundo americano. Allí se debatía el tamaño de un grado de latitud y la forma de la tierra. Los newtoníanos sostenían, siguiendo a Isaac Newton, que la tierra era una esfera achatada en los polos; y los cassinistas, que seguían al astrónomo real Jacques Cassini, afirmaban que nuestro planeta tenía la forma de un huso ceñido por la mitad. 
Para zanjar sus diferencias organizaron dos expediciones: una iría a Laponia, en el Polo Norte, y otra se dirigiría al Ecuador. La segunda, que es la que aquí interesa, estuvo encomendada al joven matemático y geodesta Charles-Marie de La Condamine, duró 10 largos años y, vista a la distancia, resultó una novela de aventuras y de viajes. Partió en mayo de 1735 y llevaba, entre otros especialistas, un astrónomo, un botánico, un dibujante, un médico y un relojero. Esa expedición reveló al mundo diversos grupos humanos, lenguas autóctonas, montañas, minas, misiones religiosas y animales (mosquitos, cocodrilos, monos, cóndores) que se movían en una naturaleza desconocida y prodigiosa:

Puede juzgarse cuál será la abundancia y la variedad de plantas en un país en que la humedad y el calor contribuyen por igual a hacerle fértil. Las de la provincia de Quito no habrán escapado, seguramente, a las investigaciones de M. Joseph de Jessieu, nuestro compañero de viaje; pero me atrevo a decir que la multitud y diversidad de árboles y de plantas que se encuentran en las márgenes del río de las Amazonas, en toda la extensión de su curso, desde la cordillera de los Andes hasta el mar, y en las orillas de diversos ríos sus tributarios, darían muchos años de trabajo al más laborioso botánico y ocuparían a más de un dibujante (La Condamine, 1941: 52-53).

Víctor Wolfgang von Hagen, en su conjunto de biografías noveladas Sudamérica los llama: grandes naturalistas en América (1945), tuvo un gran acierto al señalar que estos hombres son dueños de biografías extraordinarias pero que, sobre todo, son representantes de sus épocas. Todo lo que ellos hicieron hubiera sido diferente, o no hubiera sido, si los contextos no hubiesen tenido una importancia contundente en sus vidas.

A los 18 años de edad, La Condamine participó en una invasión a territorio español y, entre los cautivos, tenían un soldado que había estado en la colonias, proscritas para Francia e Inglaterra porque España y Portugal no querían que metieran las narices en su nuevo cuerno de la abundancia (de allí venían las especias que habían quitado la monotonía a la cocina europea, los frutos del paraíso terrenal y el oro y la plata que permitieron el nacimiento de una Europa capitalista). La descripción de los Andes y de los caudalosos ríos inflamó la imaginación de La Condamine, quien puso desde entoces todo su interés en el Nuevo Mundo.

Como la entrada a América estaba vedada para militares y comerciantes, Felipe V de España, pariente del Rey de Francia, autorizó la expedición sólo por tratarse de hombres de ciencia, pero les puso dos chaperones, Jorge Juan y Antonio de Ulloa, oficiales de la marina española de guerra.

Entraron a América por Cartagena (Colombia), que era una de las tres puertas del Nuevo Mundo (las otras dos: Veracruz, en México, y Puerto Bello en Panamá). Así los recibió el trópico:

Se deslizaron por la boca chica, llegaron hasta la bahía y casi se sintieron subyugados por los ardientes matices de las flores, el olor de la vainilla, los deliciosos perfumes de la fecunda tierra que rodeaba al gran puerto. Todo lo que veían les deleitaba y sorprendía. Vieron a los peones, vestidos de pantalones blancos y cortas blusas blancas, con sombreros de paja color oscuro, bambolearse por el malecón bajo la pesada carga de las cosas de España - cueros de Córdoba, vino de La Mancha, aceite de Jaén-y otras procedentes de todos los talleres de Europa, artículos de vidrio, fusiles y telas. Las palmeras bordeaban las playas que besaban las olas; bálsamos y acacias, ahora en plena floración, perfumaban el ambiente de las animadas calles, en los linderos de la ciudad atravesaron bosquecillos de cacaos, el tesoro más valioso que la naturaleza podía haber concedido a América, que producía la semilla con la que se fabricaba el chocolate que sólo podían comprar las gentes más ricas de París. Comieron papaya, guayaba, 
chirimoya; se atracaron hasta casi reventar del fruto dulce y agradable del zapote, entonaron rapsodias cuando probaron la piña (Von Hagen, 1963: 36).

Padecieron mosquitos, hormigas, niguas, moscas y cucarachas, pero eso no les impidió arrobarse ante la selva:

La belleza de la selva disipó sus últimas dudas. He aquí al tucán, el ave con el pico ridículamente monstruoso, que repetía sin cesar su canto Dios te dé, Dios te dé; y el campanero, cuyo canto era una sola nota melódica, que remedaba exactamente el tañido de una campana; y los colibríes que se sostenían en el aire, delante de sus mismos ojos (...) Había también quetzales, bellos y tímidos; el gallo de las rocas, una bola de plumas anaranjadas con los bordes de las alas negros (...) Los jaguares permanecían en cuclillas sobre los árboles, los monos se colgaban con sus colas de las festoneadas lianas, las ranas se pegaban a los troncos por medio de las ventosas de sus patas (Von Hagen, 1963: 62).

Para hacer sus mediciones, La Condamine, sus compañeros y sus ayudantes indígenas subieron a los Andes y bajaron a las ciudades coloniales. Los españoles y el populacho, ante tan intensa actividad, pensaron que buscaban tesoros incas o que hacían planos para dárselos a sus enemigos, los ingleses, que cobijaban a los piratas que asaltaban sus navíos cargados de oro y piedras preciosas.

En Quito, después de colocar una marca de sus mediciones al pie de la catedral, estrechó su amistad con los jesuitas, quienes la construyeron, y pudo entrar a los archivos secretos en donde vio el original del primer mapa del Amazonas, dibujado por el padre Samuel Fritz. Quiso entonces volver a su patria bajando por el Amazonas y los jesuitas le permitieron reproducir el diario del padre Fritz. Le dieron una copia del mapa y cartas de presentación para los jesuitas encargados de las misiones que hallaría en su descenso. En compañía de su amigo, el matemático ecuatoriano Pedro Maldonado, realizó la misma aventura que Orellana, 200 años antes, había llevado a cabo.

Gracias a este viaje, observó cómo la nieve derretida de los Andes, las aguas cargadas de detritus de las montañas, las corrientes formadas con la neblina y los ríos subsidiarios, iban haciendo el majestuoso caudal del Amazonas. Al hablar del gran río no pudo evitar la mención de las míticas guerreras que vivían en lo más profundo de la selva y, después de conceder el beneficio de la duda sobre su existencia, afirmó que quizá ya no se les veía porque las jóvenes decidieron no repudiar a los hombres, como hacían sus madres, y se fueron a vivir entre ellos.

Si en la selva conoció el caucho y fabricó con él una funda impermeable para uno de sus instrumentos de medición, en el Amazonas conoció el barbasco ("hierba que emborracha a los peces") y el curare. Él llevó al Viejo Mundo el caucho - del que ya habían dado noticia Hernán Cortés, Pedro Mártir de Anglería y Juan de Torquemada, pero aún sin uso industrial-y el platino.

Cuando La Condamine leyó su Relación abreviada... ante La Academia de las Ciencias estuvo en el dilema que han vivido los científicos: presentar sus estudios en términos técnicamente fríos o hacerlo con concesiones para los no iniciados; y optó por el justo medio:

Para no defraudar la expectación de aquellos que no buscan en una relación de viajes sino acontecimientos extraordinarios y pinturas descriptivas agradables de usos extranjeros y de costumbres desconocidas, debo advertirles que no encontrarán en ésta más que muy poco que les satisfaga (...) Se trataba de dar una idea del mismo en una memoria destinada a ser leída en la Academia de Ciencias. En una relación semejante, donde debía atenderse menos a divertir que a enseñar (...) He procurado elegir un término medio entre los dos extremos (La Condamine, 1941: 4-5). 
En 1774, en su patria, a los 73 años de edad —no sin antes celebrar la odisea de Isabel de Grandmaison, peruana que descendió el Amazonas sola y sin provisiones en pos de su marido el expedicionario Jean Godin des Odonais-, murió sordo y paralílico. Dejó la estafeta a un niño que, en ese entonces, tenía cinco años de edad: Alexander von Humboldt.

\section{2}

Humboldt vino a América gracias a los oficios del azar. Quería ir a Egipto, pero el bloqueo continental inglés tendido en aquel momento lo hizo dirigirse a nuestro continente. Sin embargo, cuando el destino lo embarcó hacia el Nuevo Mundo en 1799 (cinco de junio), junto con su compañero Aimé Bonpland, ${ }^{1}$ decidió resolver una incógnita que La Condamine había dejado pendiente: averiguar cómo y dónde se comunicaban el Orinoco y el Amazonas. Las fervorosas lecturas de los libros de los viajeros (La Condamine sobre todos ellos, Maurice de Nassau), Pablo y Virginia, de Bernardine de Saint Pierre, y las obras de los jesuitas refugiados en Italia (Beck, 1971: 15-55), alimentaron los sueños de Humboldt para conocer el mundo tropical. ${ }^{2}$ Había estudiado dibujo, grabado, matemáticas, geología y botánica. La carta que el rey de España Carlos IV le extendió para explorar (en tiempos en que la teoría bíblica de la creación estaba vigente) las Islas Canarias y los territorios de Hispanoamérica le permitió convertirse en el segundo descubridor de los países que visitó: México, Cuba, Venezuela y Ecuador.

Comolas circunnavegaciones europeas del momento tenían más fines colonialistas que intereses científicos, celebraremos que Humboldt, en su viaje a América de cinco años, coleccionó más de 6,000 plantas, de las cuales más de la mitad eran desconocidas. "Gracias a él, la geografía - que hasta entonces era una miscelánea de curiosidades y de datos sueltos recogidos por los viajeros en todos los países de la Tierra - alcanzó rango de ciencia" (Meyer-Abich, 1985: 19).
Humboldt fue un hombre que supo aprovechar las expectativas que su tiempo le brindaba:

El destino le favoreció presentándole en un momento crucial de la cultura de occidente. Su juventud coincidió con la época del iluminismo, del racionalismo, de la naciente afición por el paisaje, y de ella cobró poderosos motivos para el estudio de las cosas; su madurez transcurrió en los tiempos del florecimiento de las Ciencias Naturales, de la tendencia a la observación clásica y de las ansias de libertad; y su muerte a los 90 años le preservó de ver anticuarse sus ideas... (Banse, 1945: 220).

Si lo que aquí interesa es consignar la visión de la selva durante su viaje (1799-1804) a los trópicos, mismo que está consignado en Del Orinoco al Amazonas. Viaje a las regiones equinocciales del nuevo continente (1807), el cual escribió en Europa con las notas que había tomado en América, resulta iluminador el conjunto de misivas que despachó durante su periplo americano porque ellas son verdaderos compendios de lo que, con largueza, desarrolló en Viaje a las regiones equinocciales. A saber: el episodio de la muchacha que perdió un brazo entre las fauces de un cocodrilo, su descripción del barbasco y de las anguilas eléctricas, sus observaciones de los horarios con que los moscos se ceban en los humanos, los terremotos, los mercados de esclavos, Venezuela bajo el asedio de los bucaneros, la lluvia de estrellas, el olor a petróleo que emanaba de algunos manantiales, los guácharos (pájaros que guardan en sus vientres importantes cantidades de grasa) y un sinfín de observaciones antropológicas (lenguas, instrumentos musicales, alimentos, viviendas, artesanía, bailes, organización social, creencias religiosas e inhumaciones).

Un señalamiento fundamental fue la quema de selvas para tener tierras cultivables que, como hoy vemos, es una de las causas que junto con el pastoreo han propiciado la tala de la región amazónica. 
Por estas cartas nos enteramos que lo seduce la tierra americana, por paradisíaca, pero no aspira a ser un Gauguin. Mientras al pintor lo enervaban las tahitianas, a Humboldt lo absorbe el estudio; el sexo parece no tener lugar en su existencia. En América extraña el intercambio de ideas con los hombres cultos de su tiempo, por eso siempre piensa en enviar cosas a Europa, y en marcharse en pos de ellas.

Se calcula que Humboldt, en el transcurso de su larga vida, escribió más de 35,000 cartas. Unas semanas antes de su muerte, hizo publicar un anuncio en los diarios de su patria en donde suplicaba que ya no tomaran su casa como buzón (recibía entre 1,600 y 2,000 cartas anualmente) y le permitieran dedicarse a sus propias labores.

Del Orinoco al Amazonas. Viaje a las regiones equinocciales del nuevo continente es producto de un plan que Humboldt meditó durante su espera en territorio español. En una carta a Friedländer, fechada el 11 de abril de 1799, poco antes de embarcarse hacia América, tierra que consideraba salvaje y exótica, y que cuando toma sus notas califica una y mil veces de ubérrima, enuncia así sus propósitos:

¡Cómo me deleitaré en esta tierra maravillosa! Probablemente nadie se acercó jamás a aquella zona con un espíritu tan independiente y tan alegre, con ánimo tan activo. Coleccionaré plantas y animales; estudiaré y analizaré el calor, la electricidad, el contenido magnético y eléctrico de la atmósfera; determinaré longitudes y latitudes geográficas; mediré montañas, por más que todo esto no sea la finalidad del viaje. Mi verdadera y única finalidad es investigar la interacción conjunta de todas las fuerzas de la naturaleza muerta sobre la creación animal y vegetal animadas (Von Humboldt, 1997: 11).

Como puede observarse, ya está aquí el propósito que animaría la escritura de su obra magna, Cosmos (1845-1862), un cuadro general del universo en donde pondría el conocimiento singular en armonía con toda la naturaleza.

Humoldt buscaba la tierra feraz y encontró Venezuela. Vio ceibas de 40 metros de alto y 4.5 metros de diámetro; contempló arrobado 10 kilómetros cuadrados de selva sumergida en las aguas del río Temi. Fue testigo privilegiado de una América edénica en donde los naturales se batían cuerpo a cuerpo con las fieras, sin la superioridad técnica de las armas que darían ventaja a los seres humanos. Si nos atenemos al libro que consigna su periplo, podemos decir que es una especie de reportaje, una crónica de aventuras que remata en la inevitable alusión al Paraíso Terrenal:

Detrás de este seto hay un bosquecillo de cedrela, palo brasil y gayac. Las palmeras son relativamente raras; sólo de vez en cuando se levanta un ejemplar de corozo o de la espinosa piritu. Los grandes cuadrúpedos de esta zona - jaguares, tapires y pécaris se han abierto paso en el mentado seto de sausos, para bajar a abrevar en el río. Como apenas se asustan de las embarcaciones, se puede gozar del espectáculo de verlos deslizarse lentamente a lo largo de la orilla, hasta que desaparecen en la selva por una de las estrechas soluciones de continuidad. Uno se siente en un mundo nuevo, frente a una naturaleza salvaje e indómita. Ora aparece en la ribera el jaguar, la hermosa pantera americana; ora es el hocco (Crax alector), de negro plumaje y penacho, que se pasea sin prisas por la ribera. Se van sucediendo animales de los tipos más diversos. "Es como el paraíso", decía nuestro timonel, viejo indio de las misiones. Y en realidad todo recuerda aquí el estado original del mundo (Von Humboldt, 1997: 237).

En esta crónica logra el difícil equilibrio entre la puntualidad científica y el relato novelesco, pues tiene plena conciencia de que escribe para especialistas, pero también para legos. Humboldt tiene mayor capacidad narrativa que la Condamine; de aquí que se convierta 
en el modelo expresivo a seguir por Charles Darwin, teólogo que echaría por tierra la teoría de la creación divina; leía como obras religiosas los libros de Darwin en el pequeño camarote del Beagle, que sólo acogía estos volúmenes, y El paraíso perdido de Milton.

He aquí su primera imagen de la selva:

Cuando el viajero que acaba de llegar de Europa entra por primera vez en las selvas sudamericanas, se halla ante un cuadro completamente inesperado. A cada paso que da siente que se halla no en las fronteras de la zona tórrida, sino dentro de ella, en un inmenso continente donde todo es gigantesco; montañas, ríos y masas de vegetación. Si es capaz de sentir la belleza del paisaje, difícilmente podrá analizar sus múltiples impresiones. No sabe decir qué le sorprende más: si el solemne silencio de estas soledades, la hermosura de los diversos objetos y sus contrastes, o la plenitud y exuberancia de la vida vegetal. Diríase que el suelo, sobrecargado de plantas, no dispone de espacio suficiente para su desarrollo. Por doquier, los troncos de los árboles se ocultan detrás de un verde tapiz, y si se quisiera trasplantar cuidadosamente todas las orquídeas, las especies de piperáceas y aráceas que crecen en un solo algarrobo o higuera americana (Picus gigantea), se cubriría una extensa porción de terreno. Incluso los bejucos que se arrastran por el suelo trepan hasta las copas de los árboles, columpiándose de una a otra a más de 30 metros de altura. Y como quiera que así las plantas parásitas forman una verdadera maraña, el botánico corre peligro de confundir flores, frutos y hojas de distintas especies.

Seguimos varias horas a la sombra de aquellas bóvedas vegetales, a cuyo través apenas se ve de vez en cuando el cielo azul. Me parecía tanto más de color añil cuanto que el verde de las plantas tropicales suele tener una tonalidad muy intensa, que vira a pardo. Dispersas masas de rocas aparecían recubiertas de grandes helechos arborescentes. Allí vimos por primera vez nidos en forma de botellas o pequeñas bolsas colgando de las ramas de los árboles más bajos. Son obra de la admirable habilidad constructora de los tordos, cuyo canto se mezclaba con el bullicioso griterío de los papagayos y aras. Estos últimos, universalmente conocidos por los vivos colores de su plumaje, volaban siempre en parejas, mientras que los auténticos papagayos lo hacen en bandadas de varios centenares de individuos (Von Humboldt, 1997: 82-83).

Después de estas páginas iniciales, Humboldt se propuso no abundar en más descripciones cuando la manigua fuera demasiado prolija. Mientras más contundente y grandiosa aparece la naturaleza en las zonas bañadas por gigantescos ríos, más se ciñe a la elaboración de cuadros llenos de sobriedad. Sin embargo, a pesar de esta restricción autoimpuesta, llegará el momento en que reflexionará sobre la pequeñez humana:

Los caimanes y las boas son los dueños del río; el jaguar, el pécari, el tapir y los monos deambulan por la selva sin temor ni peligro: moran allí, su patria de origen. Este espectáculo de la naturaleza viva, en la que el hombre no es nada, tiene algo de paradójico y de opresivo. Aquí, en un territorio feraz, adornado de un verdor perenne, busca uno en vano la huella de la acción del hombre; se cree uno relegado a un mundo distinto de aquel en que nació (Von Humboldt, 1997: 329).

Humboldt, el último de los sabios de la Ilustración,de los que dominaban varias ramas del conocimiento, inspiró a Charles Darwin el viaje por Brasil, Tierra del Fuego e Islas Galápagos, de donde nació la teoría de la evolución. Murió en 1859, el mismo año en que Darwin publicó Elorigen de las especies. Los países en donde estuvo -México, Cuba, Venezuela, Ecuador- le llamaron su segundo descubridor. Fue modelo y estímulo para un puñado de naturalistas que siguieron sus pasos.

Para apreciar la trascendencia de sus aportaciones al conocimiento, debemos escuchar a Jaime Labastida, 
quien sostiene que Charles Darwin sería el más grande humboldtiano de la segunda mitad del siglo XIX (Labastida, 1999).

Tal como sucedió a Humbold, Charles Darwin vino a América por accidente: el capitán Fitz Roy, en un primer viaje a la Tierra del Fuego, había llevado con él a cuatro aborígenes. En Inglaterra procuró educarlos - los reyes les concedieron audiencia en atención al exotismo que representaban-, pero un día en que encontraron a la pequeña Fuegia Basket en arrumacos con su compatriota York Minster, se escandalizaron ante la posibilidad de que Inglaterra viera embarazada a una muchacha de once años de edad. Y para quitarse a esta pareja de encima decidieron organizar una nueva empresa exploratoria. Como en su viaje anterior, Fitz Roy lamentaba no haber llevado a bordo a un hombre de ciencia que recogiera muestras del mundo americano, pidió ayuda y le recomendaron a Darwin, un joven teólogo creacionista que había leído asiduamente a Byron y a Shakespeare pero que, cuando cayó en sus manos el Viaje a las regiones equinocciales, sintió vivos deseos de correr mundo, entonces se propuso aprender español.

El 27 de diciembre de 1831, parte de Inglaterra el Beagle, una pequeña embarcación de tres mástiles y treinta metros de eslora. El capitán Fitz Roy tiene 26 años de edad y lleva la misión de cartografiar las costas de América del sur. El naturalista Charles Darwin, de apenas 22 años de edad, se hará cargo de explorar las montañas y las selvas; durante todos los años que dure el viaje de circunnavegación (1831-1836), siempre tendrá a su lado El paraíso perdido, de Milton. ${ }^{3}$

Si bien para esta época ya se conocían todos los continentes, los comerciantes y hombres de ciencia decidieron inventariar las riquezas naturales del planeta.

Darwin tenía conocimiento profundo del Viaje a las regiones equinocciales, que había escrito Alexander von Humboldt después de haber remontado, en 1799, más de 2,000 kilómetros del río Orinoco, y admiraba las ideas del francés Lamarck, quien sostenía la tesis de que los animales no han sido siempre iguales ya que se transforman en función de las necesidades y las exigencias del medio en que han vivido.

El periplo de Darwin, que le permite inventariar animales, plantas, fósiles e islas, dura cinco años; su fruto más importante es El origen de las especies a través de la selección natural o la lucha por la existencia, cuyos 1,250 ejemplares se agotaron el 24 de noviembre de 1859, día de su aparición. La historia de la escritura y vicisitudes de este libro, que fue revolucionario porque planteó la idea de que el hombre pertenecía a la familia de los monos y ubicó al ser humano en el reino animal, contradiciendo la idea bíblica de que Adán y Eva fueron creados por Dios, convirtieron la vida de este joven inquieto en una novela de aventuras.

Nadie imaginaría que las Islas Galápagos, también llamadas Islas Encantadas, que Ecuador convirtió en prisión para personas cuyo delito era haber participado en alguna revuelta social, propiciarían el nacimiento de la teoría de la evolución, que revolucionaría no sólo las ciencias, sino también la moral y las religiones. Las islas, formadas con lava surgida del corazón del océano, hornos de cielo sombrío que no conocían los mamíferos, a Darwin y al capitán Fitz Roy les parecieron adecuadas para un pandemonium. Gracias a las corrientes marinas y a la visita de las aves, se habían poblado de cactos y líquenes que servían de alimento a las iguanas y a las gigantescas tortugas (galápagos) de 90 kilos de peso. La isla Chatham era traspasada por vapores subterráneos y tenía volcanes activos.

$\mathrm{Al}$ advertir que los caparazones de las tortugas eran distintos en cada isla, Darwin llegó a la conclusión de que, si bien todas tenían una misma raíz, cada grupo se había diferenciado por sus condiciones de vida. Esto y los fósiles que encontró en la Patagonia le hicieron pensar que había una transmutación en los seres vivos. 
Si tenemos presente que los prisioneros vivían en cuevas, al estilo Robinson Crusoe, las mismas cuevas que habían servido de refugio a los piratas, quienes bautizaron las islas, trazaron su mapa y en los acantilados bruñidos por la brisa y las aguas del mar habían pintado con rojo los nombres de los barcos que encontraron refugio en el archipiélago, veremos que la ciencia y la historia no anduvieron muy lejos de la literatura. Es más:

Se ha insistido en que la novela de aventuras está íntimamente unida a ese sueño ecologista que, a partir de Rousseau, gana a buena parte de la inteligencia europea y encuentra en el mito del buen salvaje su más afortunada expresión. Es una teoría muy extendida que, sin embargo, convendría revisar.

Pienso que la primera gran novela de aventuras, la obra que abrirá un camino masivamente transitado, es el Robinson Crusoe. Pues bien, Defoe publica su maravillosa novela en 1719, es decir, bastantes décadas antes de que se popularicen las teorías de Rousseau. Y curiosamente, la popularización de las ideas de Rousseau se verá reforzada por las exploraciones de Bouganville y Cook, que descubren a los europeos la existencia del último paraíso en las lejanas Islas de la Sociedad (Martínez-Menchén, 1976: 46).

Como dato adicional, no olvidemos que Defoe escribió su novela basado en un testimonio del antiguo pirata Woode Rogers, quien rescató a Alexander Selkirk en la isla de Juan Fernández y lo llevó sano y salvo a Inglaterra.

Pero como en el presente texto lo que se persigue es mostrar la visión del trópico en general y de la selva americana en particular en los libros más literarios que científicos de algunas distinguidas personalidades, me referiré a El viaje del Beagle (1839), diario que contiene los cuadernos que Darwin llevó en los casi cinco años que duró su peregrinar por Sudamérica, y algunas islas como Tahití, Madagascar y la Isla de Francia.
En El viaje del Beagle, Darwin da cuenta de tipos humanos, peces, plantas, protozoarios, suelos, flores, fósiles, árboles, formaciones geológicas, ríos, atolones, llanos, bosques, climas, vientos, villorrios, alimentos, islas, montes, terremotos, tsunamis, etcétera. Si bien la selva le parece monótona pero sublime, no se priva de la cacería:

Mi compañero había matado la víspera a dos grandes monos barbudos; esos animales tienen colas prensiles, cuyo extremo puede soportar el peso del cuerpo del animal aún después de muerto. Uno de ellos quedó fijo a una rama y hubo que cortar un árbol grueso para alcanzarle, lo cual se consiguió muy pronto. Aparte de estos monos, sólo matamos algunos loritos verdes y algunos tucanes (Darwin, 1983: 39).

Como dato curioso para la literatura hispanoamericana, tenemos que en Argentina Darwin conoce a Rosas, se asoma a un gran corral y nos da su versión de lo que Esteban Echeverría iba a convertir en "El matadero". De aquí deriva también la imagen reiterada de unos indios belicosos que nada tienen que ver con los que inspiraron el indigenismo de Guatemala, México, Ecuador, Perú y Bolivia.

En Tahití, después de ver nacer el fuego como el hombre primitivo, hace este apunte significativo:
Había además otras frutas silvestres y plantas útiles. El torrente pequeño, además de su agua fresca, producía anguilas y cangrejos. No podía menos que admirar esta escena y compararla con un punto no cultivado de las zonas templadas; y cada vez me convencía más de que el hombre, o al menos el hombre salvaje, cuya razón está todavía en parte sin desarrollar, es hijo de los trópicos (Darwin, 1983: 479).

De aquí al tópico de la civilización había una corta distancia: 
Los habitantes de Tahití son en realidad encantadores. Tienen sus facciones tal dulzura de expresión que no es posible imaginar que sean salvajes; $y$ es tan grande su inteligencia que progresan en la civilización con suma rapidez (Darwin, 1983: 472).

Cuando Darwin habla de la Isla Mauricio, antes Isla de Francia, que tan importante fuera como detonador de la escritura de Pablo y Virginia, de Bernardine de Saint Pierre, pondera que tiene un escenario operístico como signo de civilización vencedora de la naturaleza, sin imaginar siquiera que el auge del caucho en Sudamérica, a finales del siglo XIX, propiciaría la construcción de un escenario para ópera, enclavado en el corazón de la Amazonía, empresa alucinada que iba a alimentar los libros de Marcio Souza y daría pie a Fitzcarraldo, destacada película de Werner Herzog. He aquí sus palabras:

Aunque desde hace muchos años pertenece la isla a Inglaterra, reina siempre en ella el carácter francés. Los residentes ingleses hablan en francés a los criados. Todas las tiendas son francesas; hasta podría decirse, creo, que Calais y Boulogne se han hecho mucho más inglesas que la isla Mauricio. Hay aquí un teatrito precioso donde se cantan muy buenas óperas. Con alguna sorpresa vimos librerías bien surtidas. La música y la lectura nos indican que nos acercamos al antiguo mundo de la civilización; porque en verdad Australia y América son mundos nuevos (Darwin, 1983: 560)

$\mathrm{Y}$, casi al final de este diario de viaje, apunta lo que se volverá un lugar común con el correr de los años, de la literatura y del urbanismo:

Bueno es recordar que bajo los trópicos no desaparece, ni aun junto a las grandes poblaciones, el lujo brillante de la naturaleza, pues los trabajos artificiales del hombre desaparecen muy pronto bajo la potente vegetación de aquellas tierras (Darwin, 1983: 571).

Darwin describió la vida tropical como botánico, geólogo y entomólogo pero, al final de sus minuciosos cuadernos, ante las costas de Brasil (país cuya naturaleza admiraba a pesar del rechazo que sentía por su régimen esclavista), con los ojos de un europeo, apunta que todo lo que mostró con detalles científicos, constituye un paisaje que, a la distancia, con todo el arrobamiento que produce, no pone en las manos la vida palpitante, llena de sonidos y movimientos. Pero la lectura de su diario, en sus diferentes etapas, sí fue capaz de entregar ese todo, ese Nuevo Mundo que vinieron a ver los hombres de ciencia que debieron dar cuenta, en amenos y estéticos volúmenes, de sus dilatadas investigaciones:

He deseado encontrar términos capaces de expresar mis sensaciones, mientras me paseaba a la sombra de estas selvas espléndidas. Todos los epítetos me parecían muy débiles para dar a los que no han visto las regiones intertropicales la idea de la sensación de gozo que se experimenta. Ya he dicho que es imposible formar concepto de lo que es la vegetación de los trópicos, viendo las plantas encerradas en un invernadero; pero debo insistir aún sobre este punto. Todo el paisaje es un inmenso invernadero rebosante, creado por la naturaleza misma, pero del cual ha tomado posesión el hombre, embelleciéndolo con preciosas casas y jardines (...) Entre los cuadros que más honda impresión han causado en mi espíritu, ninguno tan sublime como el aspecto de las selvas vírgenes en que no hay vestigios del paso del hombre (Darwin, 1983: 472 y 580).

\section{4}

La senda naturalista inaugurada por los personajes antes mencionados se alargaría como una cadena si la escribiésemos: en 1849, Richard Spurcefue a la Amazonía 
inspirado por Darwin. Sus Notes of a Botanist on the Amazon and the Andes (1849-1864), publicadas y resumidas por Alfred Russel Wallace... Cada uno de los sabios viajeros antes mencionados tuvieron sus seguidores, tal como hace constar Hans Joachim Wulschner en su antología de naturalistas, aventureros o pintores alemanes: Del Río Grande al Plata:

Desde mediados del siglo XVI, cuando Nikolaus Federmann, Ulrico Schmidl y Hans Staden narraron sus impresiones y experiencias en fantásticas crónicas sobre el Nuevo Mundo, se mantuvo latente en Alemania y otros países de habla teutona, un vivo interés por los asuntos sudamericanos. Durante los dos siglos y medio que siguieron, la paciencia de este círculo de lectores fue sometida a una prueba pues la exploración del subcontinente hacía progresos insignificantes $y$, en consecuencia, los informes llegaban en forma esporádica. La situación cambió de súbito después de la expedición de Alexander von Humboldt por América del Sud entre los años 1799 y 1804 , que hizo época en el verdadero sentido de la palabra (Wulschner, 1976: 7).

Deseo terminar con el más bello libro de Claude LévyStraus, un científico social que puso en entredicho la idea de que el trópico era una fiesta: Tristes trópicos (1955). Esto puede parecer un capricho, pero ante tal cantidad de materiales sobre nuestro tema hay que parafrasear a Borges, pues así como un libro nunca se termina sino solamente se abandona, hay artículos que, por la vastedad de su materia, deben darse por concluidos en un momento dado.

Claude Lévi-Strauss, filósofo, antropólogo y sociólogo, está vinculado a Latinoamérica mediante uno de sus libros más importantes y accesibles, propiciado en Brasil con un título provocador, Tristes trópicos; echa mano de un adjetivo insólito para un escenario tradicionalmente asociado con el paraíso terrenal y las tentativas utópicas.
Sin embargo, el título y algunas de sus páginas crean unas expectativas que, finalmente, abandonará el escritor. Al comienzo del volumen escribe: "Odio los viajes y los exploradores"... y Tristes trópicos es producto de una vida de viajero. Lo que sólo sabremos al avanzar por el volumen es que Lévi-Strauss rechaza los libros oficiosos que quieren producir un efecto exotista y poner por alto la intrepidez de quien vivió las aventuras. Además, los recientes libros de viajes dan una visión de un mundo que ya no existe: al fondo de las fotografías con nativos aparece tirada una lata en donde se cocinan los alimentos.

En el libro de Lévi-Staruss hay fotos de aborígenes desnudos, despiojándose, mujeres amamantando, monos exóticos, grupos danzando, personas con tatuajes profusos... Sí, todo eso es cierto, pero no están como elementos decorativos, sino como una muestra del mundo al que, todavía, el autor tuvo acceso en 1935.

Como bien sabemos, Lévi-Strauss formuló sus teorías de las sociedades calientes y las frías; las primeras son las tecnificadas que producen entropía, las segundas son conservadoras y ecológicas. Los contemporáneos primitivos que estudió el autor no son seres humanos inferiores, simplemente el medio los aisló y en ellos pudo basarse el antropólogo para plantear cómo operaba el pensamiento de los seres humanos que no estaban sometidos al vértigo civilizatorio. El pensamiento salvaje, que de salvaje no tiene nada ("el hombre siempre ha pensado bien"), es natural y espontáneo, riguroso y ordenado; no ha sufrido la influencia del saber urbano, de la cultura libresca. Es un pensamiento no domesticado para la producción (resolver ecuaciones, hacer cálculos de probabilidad) y, como es ágrafo, rige en una sociedad más igualitaria. ¿Dónde podía observar el antropólogo los mitos, rituales, cuerpos tatuados y postulados mágicos sino entre los pocos grupos que se habían mantenido apartados de las ciudades, en el corazón mismo del Brasil? Cerdos salvajes, pirañas y murciélagos eran inevitables en un libro como éste. 
Tristes trópicos está escrito con los viajes y estudios que el autor realizó en Asia, África y América Latina, vale decir, en ámbitos coloniales que no son los hegemónicos países europeos. Pero fue a esos lugares no en busca de materiales turísticamente explotables, sino para estudiar grupos en los que podía observar los elementos que conformaron sus propuestas sobre el pensamiento salvaje, o pensamiento natural, mismos que le sirvieron para formuar sus teorías que lo convirtieron en el reinventor de la antropología moderna.

Si la tradición, empezando por el Diario de Cristóbal Colón y continuando con el primer libro de un hombre de ciencia en América (Relación abreviada de un viaje hecho por el interior de la América meridional, de Charles Marie de La Condamine), forjó en las tierras ecuatoriales de nuestro continente la idea de un paraíso terrenal, Lévi-Strauss tuvo que internarse en las regiones inhóspitas del Matto Grosso, en el sertón y en la selva para encontrar hombres que estuvieran al margen de las sociedades urbanas. Naturalmente llegó a un trópico no turístico en el que sí encontró a las sociedades naturales que buscaba, pero éstas vivían en regiones aisladas, entre pantanos, acantilados y caudalosos ríos, víctimas de la miseria y carentes de medios de transporte y condiciones de higiene:

Los trópicos no son tanto exóticos cuanto pasados de moda. Lo que los caracteriza no es la vegetación, sino menudos detalles de arquitectura, así como la sugestión de un género de vida que, antes que convencernos de haber franqueado inmensos espacios, nos persuade de que hemos retrocedido en el tiempo (...) fui hasta el extremo del mundo en busca de lo que Rousseau llama los progresos casi insensibles de los comienzos (...) yo había perseguido la conquista de un estado que - otra vez dice Rousseau - no existe, quizá nunca existió, probablemente no existirá jamás y del cual, sin embargo, es preciso tener nociones justas para juzgar bien nuestro presente (LeviStrauss, 1976: 73 y 315).

Sin embargo, su primera impresión de la selva brasileña fue no sólo amable, sino además coincidente con la que realizaría el novelista guatemalteco Virgilio Rodríguez Macal:

Desde afuera, la selva amazónica parece un montón de burbujas congeladas, una plantación vertical de tumefacciones verdes; se diría que un trastorno patológico ha afligido uniformemente al paisaje fluvial. Pero cuando reventamos la funda y entramos, todo cambia: desde dentro, esa masa confusa se transforma en un universo monumental. La selva deja de ser un desorden terrestre; parece un nuevo mundo planetario, tan rico como el nuestro, al cual hubiera reemplazado.

Cuando la vista se acostumbra a reconocer esos planos aproximados y la mente no puede superar la primera impresión de aplastamiento, se descubre un sistema complicado. Se distinguen pisos superpuestos que a pesar de las rupturas de nivel y de los desórdenes intermitentes reproducen la misma construcción: primero, la cima de las plantas y de las hierbas que llegan a la altura del hombre; por encima, los troncos pálidos de los árboles y las lianas, que gozan brevemente de un espacio libre de toda vegetación; un poco más arriba, esos troncos desaparecen, ocultos por el follaje de los arbustos o la floración escarlata de los bananeros salvajes, las pacovas; los troncos resurgen por un instante de esa espuma para perderse nuevamente entre la floración de las palmeras; vuelven a salir en un punto más elevado aún, donde se destacan las primeras ramas horizontales, desprovistas de hojas pero sobrecargadas de plantas epífitas —orquídeas y bromeliáceas-como el velamen de un navío; y casi fuera del alcance de la vista ese universo se cierra en vastas cúpulas, ya verdes, ya sin hojas, pero entonces recubiertas por flores blancas, amarillas, anaranjadas, 
púrpura o malva, el espectador europeo se maravilla al reconocer allí la frescura de sus primaveras, pero en una escala tan desproporcionada que la majestuosa floración de los fuegos otoñales se impone a él como único término de comparación.

A esos pisos aéreos responden otros, bajo los mismos pies del viajero. Pues sería una ilusión creer que se camina sobre el suelo, hundido bajo un entrecruzamiento inestable de raíces, vástagos, guedejas y musgos; cada vez que el pie trastabilla, hay riesgo de caer en profundidades a veces desconcertantes... (Levi-Strauss, 1976: 340-341).

Su visión de la selva es diversa, como la selva misma, la entrega como un ámbito que propicia la molicie de los seres humanos, pero también como escenario paradisíaco:

\begin{abstract}
Los árboles temblaban más a causa de los monos que de las hojas; se hubiera dicho que en sus ramas bailaban frutos vivientes. Bastaba con extender la mano hacia las rocas a flor de agua, para rozar el plumaje de jade de un gran mutum con pico de ámbar o de coral, o de un jacamim, tornasolado en azul, como el labrador. Esos pájaros no huían de nosotros; pedrerías vivientes que erraban entre las lianas chorreantes y los torrentes frondosos contribuían a reconstruir delante de mis ojos asombrados ese cuadro del taller de los Brueghel, donde el paraíso, ilustrado por una tierna intimidad entre las plantas, los animales y los hombres, lleva a la edad en que el universo de los seres aún no había consumado su escisión (Levi-Strauss, 1976: 329-330).
\end{abstract}

Lévi-Strauss, con Rousseau, no idealiza al hombre natural. Lo mejor le parece un justo medio entre la indolencia del estado primitivo y la explosión de la civilización mecánica. De aquí que la conclusión de su libro sea oscura: los seres humanos no han hecho sino entropía. Han destruido la naturaleza de tal modo que es imposible volver al mundo habitado por los grupos que estudió en diversos libros.

\section{Notas}

${ }^{1}$ Este médico inclinado a la botánica nació en San Bartolomé de la Rochela el mismo mes y el mismo año en que Jean Godin des Odonais regresó a este lugar con su esposa doña Isabel, después del trágico periplo de ésta por el Amazonas. Durante toda su juventud, Bonpland escuchó contar esta odisea de la esposa del compañero de La Condamine.

${ }^{2}$ El 16 de octubre de 1,800, en una carta a A. Fourcroy, escribe: "iQué placer, mi digno amigo, vivir en medio de estas riquezas de la naturaleza tan majestuosa e imponente! Se ha cumplido el más anhelado y ardiente de mis deseos; en mitad de los bosques espesos del Río Negro, rodeado de tigres y cocodrilos feroces, el cuerpo martirizado por las picaduras de los formidables mosquitos y hormigas, no habiendo ingerido durante tres meses alimento distinto del agua, bananas, pescado y yuca...", Alexander von Humboldt, Cartas americanas, Traducción de Marta Traba, compilación, prólogo, notas y cronología de Charles Minguet, Caracas, Biblioteca Ayacucho, 2da. ed., 1989, p. 47.

${ }^{3}$ Sir Julian Huxley y H. D. B. Kettlewel, Darwin, Barcelona, Biblioteca Salvat de Grandes Temas, 1984.

\section{Bibliografía}

Banse, Ewald (1945), Los descubridores de la tierra, Traducción de Sebastián Bachs, Barcelona: IberiaJoaquín Gil.

Beck Hanno, Alexander Von Humboldt (1971), Traducción de Carlos Gerhard, México: Fondo de Cultura Económica (Grandes Obras de Historia).

Darwin, Charles (1983), El viaje del Beagle, s/trad., Barcelona: Guadarrama (Punto Omega).

Huxley, Julian y H.D.B Kettlewel (1984), Danwin, Barcelona: Biblioteca Salvat de Grandes Temas. 
Labastida, Jaime (1999), Humboldt, ciudadano universal, México: Siglo XXI/El Colegio Nacional/F. C. E./ Secretaría de Educación Pública.

La Condamine, Charles-Marie de (1941), Relación abreviada de un viaje hecho por el interior de la América meridional, Traducción de Federico Ruiz Morcuende, Madrid: Espasa Calpe.

Lévy-Strauss, Claude(1976), Tristestrópicos, Traducción de Noelia Bastard, Buenos Aires: Editorial Universitaria. Martínez-Menchén, Antonio (1976), "La novela de aventuras y la naturaleza perdida”, en El Viejo Topo, Barcelona, núm. 14 extraordinario, s./f.

Meyer-Abich, Adolf (1985), Humboldt, Traducción de Rosa Pilar Blanco, Barcelona: Salvat Editores.
Von Humboldt, Alejandro (1989), Cartas americanas, Traducción de Marta Traba, compilación, prólogo, notas y cronología de Charles Minguet, Caracas: Biblioteca Ayacucho, 2da. ed.

Von Humboldt, Alexander (1997), Del Orinoco al Amazonas. Viaje a las regiones equinocciales del Nuevo Continente, s./ trad., Barcelona: Grupo Editorial Ceac (Caravansari).

Wolfang Von Hagen, Víctor (1963), Sudamérica los llama: grandes naturalistas en América, Traducción de Teodoro Ortiz, México: Editorial Grijalbo.

Wulschner, Hans Joachim (1976), Del Río Grande al Plata, Traducción de Willy Kemp, Buenos Aires: Editorial Sudamericana. 